\title{
Tribos, Cacicados ou Estados? A dualidade e centralização da chefia na organização social da América pré-colombina
}

\author{
Marcia M. Arcuri*
}

\begin{abstract}
ARCURI, M. M. Tribos, Cacicados ou Estados? A dualidade e centralização da chefia na organização social da América pré-colombina. Revista do Museu de Arqueologia e Etnologia, São Paulo, 17: 305-320, 2007.
\end{abstract}

Resumo: Este artigo apresenta uma breve discussão bibliográfica dos pressupostos teóricos que fundamentaram as interpretações arqueológicas e etnográficas recentes sobre as formas de organização política e social na América pré-colombiana. Procura-se demonstrar que a exigüidade de argumentos pautados no aprofundamento de nossa compreensão das cosmovisões ameríndias, sobretudo no que tange suas noções de poder e chefia, pode ser um dos principias fatores limitantes ao debate acadêmico sobre a complexidade social e as relações de poder na América indígena.

Palavras-chave: Política - Religião - Chefia - América Indígena - Espacialização.

$\mathrm{O}$ s estudos antropológicos sobre a América indígena publicados nas décadas de 1940, 1950 e 1960 deram origem a um intenso debate sobre a natureza da organização social e política dos povos amazônicos, uma polêmica que influenciou de forma determinante as investigações arqueológicas e etnológicas brasileiras dos últimos cinqüenta anos.

Em 1962, Elman Service publicou Primitive Social Organization: An Evolutionary Perspective, propondo que os grupos indígenas que viveram na América do Sul teriam atingido diferentes estágios de complexidade na sua organização social. Esses estágios poderiam ser medidos em quatro níveis de uma escala evolutiva descrita a partir do modelo de tipologias sociais anteriormente apresentado

(*) Museu de Arqueologia e Etnologia da Universidade de São Paulo. Pós-doutorado. marcuri@usp.br por Julian Steward (1948), em The Handbook of South American Indians, publicação a partir da qual o conceito de "chiefdom", ou chefia, passava a ser amplamente debatido nos estudos sobre a Amazônia. ${ }^{1}$

Com o objetivo de explicar os estágios evolutivos de diferentes agrupamentos humanos e suas formas de adaptação ao meio ambiente, Julian Steward desenvolveu um modelo determinado pelas relações entre os modos de produção, a organização social e as formas de exercício político de uma determinada sociedade. Sua teoria baseou-se em moldes evolucionistas cujos parâmetros vislumbravam

(1) Com a publicação do The Handbook of South American Indians, Kalervo Oberg seria o primeiro a aplicar o modelo de Steward às populações das terras baixas da América do Sul, discutindo a forma de organização política das populações indígenas do Xingu que, segundo o autor, não apresentavam chefias centralizadas (Oberg 1949). 
as formas de organização social com poder centralizado, a produção de excedentes e a hegemonia político-cultural, ou seja, critérios espelhados no modelo ocidental de "Estado", como meta civilizacional. No extremo oposto à categoria de maior complexidade, identificada no Estado, estariam as sociedades marginais classificadas como "bandos". Esses seriam grupos caçadores-coletores nômades que estariam predestinados ao "primitivismo", pois suas formas de subsistência limitavam-se à escassez de recursos e às precárias condições de adaptação a ambientes inóspitos. Em um segundo estágio viriam as "tribos", ou sociedades agricultoras assentadas de forma mais permanente. Esses seriam os grupos ligados por laços de sangue, cujas relações de linhagens determinavam-se pela ausência de poder centralizado. $\mathrm{O}$ terceiro estágio de desenvolvimento social seria o dos "cacicados" (no inglês, chiefdoms). No modelo de Steward, os cacicados diferenciavam-se pela introdução da institucionalização do poder político e religioso, dando espaço às hierarquias sociais marcadas pela especialização técnica de indivíduos, ou grupos, reconhecidos por sua função social ou trabalho. A identidade grupal dos cacicados transcendia os limites das relações por laços sanguíneos. Por fim, no quarto e mais avançado estágio de complexidade, viria o "Estado". Seriam sociedades que teriam atingido alto grau de desenvolvimento econômico, organizadas sob a égide de um sistema político de alianças diplomáticas, com controle coercitivo e teriam como principais características internas a densidade populacional, a intensificação da produção agrícola e pastoril, a burocratização do poder público e a estratificação social.

Obviamente, Steward não partia exclusivamente de observações pessoais. Conforme já apontado por Thomas Meyers, no Handbook of Middle Amercican Indians, Steward cita seu contemporâneo Paul Kirchhoff (1948), autor do Handbook of Middle American Indians, como o primeiro a chamar a atenção para a superioridade dos povos circuncaribenhos em relação à simplicidade que caracterizava os grupos amazônicos, tidos como opostos às sociedade mais complexas dos Andes centrais (Meyers 1999: 82). Meyers aponta Kirchhoff, e também Alfred Métraux (1942), como as principais influências à elaboração da "inexata teoria de Steward, que atribui à limitação dos recursos ambientais da floresta tropical amazônica o fator determinante para a distinção no grau de complexidade desses povos em relação às sociedades circuncaribenhas" (Meyers 1999: 93).

Conforme mencionamos, este modelo evolucionista de tipologias sociais serviu de pano de fundo para o desenvolvimento de inúmeros projetos de investigação científica que buscavam preencher lacunas na história da América indígena, ao longo de todo o século vinte. Entre os principais os que discutem esta temática, seja de forma teórica ou em estudos de casos, destacam-se os trabalhos de Betty Megers (1954, 1971, 1973, 1975); Betty Meggers \& Clifford Evans (1957); Marshall Sahlins (1960, 1985); Michael Coe (1961); Donald Lathrap (1968, 1970, 1974, 1977); Carl Sauer (1952); Robert Carneiro (1970); Patrick Helms (1979); José Brochado (1980); Warren DeBoer (1981); Thomas Meyers (1981, 1982, 1999); Antônio Porro (1985, 1996); Anna Roosevelt (1987, 1989); José Oliver (1998); Carlos Fausto (2001, 2005); Denise Gomes (2005); Denise Shaan (2001, 2004); Eduardo Góes Neves (1996, 1999a, 1999b, 2001); Michael Heckenberg (1996, 1998, 1999a 1999b); James Petersen (2000) e Petersen, Neves e Heckenberg (2001), entre outros.

Este artigo não pretende contribuir com dados novos ou esclarecedores à polêmica discussão sobre existência de cacicados entre os povos amazônicos. No Congresso da Sociedade de Arqueologia Brasileira, realizado em 2007, pudemos observar o claro interesse da comunidade arqueológica pelo debate sobre o tema no concorrido simpósio Cacicado Amazônico, debatendo complexidade social na floresta tropical, que reuniu as comunicações dos especialistas: Carlos Fausto, Denise Shaan, Eduardo Góes Neves e Michael Heckenberg. Ainda que tenham sido apresentados distintos vieses de análise, pertinentes aos resultados de cada um dos trabalhos expostos, acreditamos que as 
propostas interpretativas não são excludentes, pois contemplam dados suficientes para justificar a presença, nas "terras baixas", da complexidade social originalmente atribuída unicamente às chamadas "altas culturas" da Mesoamérica e dos Andes. Esta é uma questão que há muito vem norteando nosso trabalho, no que concerne às relações entre as chefias políticas e religiosas e às relações centro x periferia, nos períodos de hegemonia da Tríplice Aliança, liderada pelos mexicas (os astecas) e do Tahuantinsuyu inca. Nesse sentido, lançamos aqui uma pergunta contundente aos resultados obtidos em anos de pesquisa sobre a natureza dos domínios político e religioso dos mexicas e dos incas: qual o sentido de adotarmos o modelo ocidental de "Estado", centralizador e unificado, para estudarmos sociedades que fundamentam a organização social, a espacialização, as relações políticas e o universo religioso na dualidade?

Cabe lembrar, que foi no trabalho de Elman Service intitulado A Origem do Estado e da Civilização, publicado em 1975, que a discussão sobre o conceito de chefia comparado às formas de organização política das chamadas "sociedades igualitárias”, ainda nos moldes do modelo teórico de Steward, ganhou ênfase. No texto citado, Service fundamenta sua argumentação discutindo a natureza do poder e das leis, as formas de liderança e o surgimento do poder coercitivo. É interessante notar que essas mesmas questões vinham sendo também discutidas, com rigoroso embasamento teórico, por Pierre Clastres, que um ano antes havia publicado A Sociedade contra o Estado.

No que concerne ao aparecimento do Estado, Service apóia-se na definição de Gordon Childe, que explicava a origem das primeiras 'civilizações' como resultado de uma "revolução urbana" que se fundamentava nas seguintes características: a formação de agrupamentos populacionais variando entre sete e vinte mil habitantes, a presença de grupos de trabalhadores especializados habitando a área urbana (artesãos, mercadores, sacerdotes etc.), a produção de excedentes agrícolas destinados a um governo centralizado, a presença de edificações públicas monumentais, a formação de elites governantes, uma produção 'artística' sofisticada, a assimilação e controle de conhecimentos matemáticos e astronômicos, o uso de linguagens codificadas (escritas), o estabelecimento de redes de comércio de longa distância e a institucionalização política da chefia baseada no poder coercitivo (Service 1975: 7).

Ainda que seja impossível negar a coerência dessa associação entre a estratificação, a burocratização e a coerção nas formas de poder entre as sociedades complexas de alta densidade populacional, pretende-se demonstrar neste artigo que não apenas a concepção imprecisa das noções de chefia mas, sobretudo, a conseqüente identificação do poder centralizado como base fundamental para a formação do Estado, são problemas ainda pouco resolvidos na literatura sobre as formas de organização social na América pré-colombiana.

Pesquisas realizadas nos últimos vinte anos proporcionaram avanços no conhecimento que demonstram que os quatro tipos de agrupamento descritos por Steward tornaramse inadequados à tarefa de tentar melhor compreender o passado da América, pois desconsideram elementos da cosmovisão ameríndia fundamentais às noções de organização social e política. Esta discussão recai, sobretudo, no debate que envolveu a definição de fronteiras idiossincráticas que pudessem precisar a comparação das sociedades enquadradas na tipologia dos cacicados, e aquelas caracterizadas pelo estágio de evolução 'tribal', ou seja, as sociedades chamadas igualitárias.

Seria impossível não atribuir o principal avanço neste debate teórico aos estudos etnográficos realizados sobre os povos da Amazônia, e Brasil Central, nos últimos trinta anos. Contudo, os dados levantados pelas pesquisas arqueológicas neste mesmo período agregam de forma significativa, abrindo as perspectivas de análise, a nosso ver, para uma completa revisão teórica. ${ }^{2}$ Surge daí um componente crucial ao debate:

(2) Destaca-se aqui o sistemático trabalho que vem sendo realizado pelo Projeto Amazônia Central, inaugurado em 1995, sob a coordenação dos arqueólogos Eduardo Góes Neves, Michael Heckenberger e James Petersen. 
a somatória de evidências que testemunham a presença de sociedades complexas na Amazônia Central, uma área que segundo a tipologia de Steward era ocupada apenas por grupos da categoria das tribos. Em suma, os dados que sustentam a produção acadêmica atual sobre a Amazônia tornaram-se os principais indicadores da necessidade de buscarmos novos parâmetros para a investigação das sociedades ameríndias e, nesta linha de raciocínio, este artigo propõe indagarmos até que ponto esses avanços científicos nos permitem questionar, também, a existência de sociedades estatais na América pré-colombiana. Se aceitamos que foi justamente a incompreensão de certas noções específicas de chefia o que mais prejudicou as interpretações evolucionistas que se pautaram exclusivamente em teorias ambientais, assim como a inconsciência, naquela época, de que era a dinâmica da oposição de forças duais complementares o principal alicerce das cosmovisões ameríndias, não teria a idéia de centralização do Estado nas mãos de um único governante também distorcido as análises sobre a organização política das sociedades consideradas estatais?

Para discutirmos a hipótese de que a crítica ao modelo tipológico de Steward aplicado às sociedades ameríndias deve estender-se na discussão sobre o conceito de Estado, será necessário abordar três aspectos teórico-metodológicos que, a nosso ver, são indissociáveis e fundamentais ao estudo sobre a América Pré-colombiana: o primeiro deles refere-se aos alcances e limites da interpretação das evidências arqueológicas à luz dos relatos etno-históricos, sobretudo dos Cronistas dos séculos XVI e XVII, assim como sua imprescin- dível comparacão aos dados etnográficos atuais; ${ }^{3}$ o segundo concentra-se na já enunciada má interpretação do significado do conceito de "chefia", assim como outros tais como "poder", "guerra", "governo" e tanto quanto são aqueles que nos servem de ferramenta para o estudo das sociedades ameríndias; e em terceiro lugar não podemos ignorar que o debate acadêmico dos últimos cinqüenta anos nos remete à associação dos fatores econômicos (economia de subsistência, aproveitamento de recursos, tecnologia de produção, agricultura intensiva e acúmulo de excedentes) e culturais (tradições, cosmovisões e regras de convívio político e social) que estavam em pauta nas histórias de tão diversas sociedades ameríndias, fatores esses que só agora podem ser analisados segundo melhores definições contextuais.

O primeiro aspecto citado, sobre o diálogo entre as evidências arqueológicas, etno-históricas e etnográficas, está intimamente ligado ao inegável alcance dos trabalhos de abordagem multidisciplinar. Muitos dados são necessários para se discutir o grau de desenvolvimento de uma determinada sociedade. Se, por um lado, a ação interdisciplinar encontra forte resistência nos meios acadêmicos mais conservadores, por outro, as referências às pesquisas realizadas nessa linha tornam-se cada vez mais comuns. Um bom exemplo pode ser conferido nos textos publicados em A História do Índio no Brasil, organizado por Manuela Carneiro da Cunha. Conforme aponta a autora, na introdução:

\section{"Sabe-se pouco da história indígena}

do Brasil: nem a origem nem as cifras de população são seguras (...), mas a
(3) Em uma recente publicação sobre o culto da divindade mesoamericana Tezcatlipoca, Guilhem Olivier nos lembra que "a utilização de materiais separados cronologicamente, às vezes por vários séculos, foi alvo de sérias críticas... A propósito das realizações artísticas sobre as quais não dispomos de testemunhos escritos contemporâneos, George A. Kluber, baseando-se no 'princípio de disjunção' elaborado por Erwin Panofsky, considerou que a continuidade das formas não implica a continuidade dos significados, e só 'a evidência intrínseca’ permite-nos analisar essas obras arcaicas. Em oposição a esta teoria, [muitos] autores... sustentaram, com justa razão, a legitimidade de uma utilização crítica das fontes escritas do século XVI para melhor se compreender a arte mesoamericana anterior a àquela época. Recorrer às investigações etnográficas para interpretar certos aspectos da religião pré-colombiana pode suscitar também sérias reservas... No entanto, vários investigadores souberam integrar, de forma fortuita, testemunhos etnográficos em seus trabalhos dedicados ao México antigo" (Olivier 2004: 24-25). 
pesquisa arqueológica veio corroborar o que os cronistas diziam: a Amazônia, não só na região de várzea, mas em suas várias áreas de Terra Firme, foi povoada durante longo tempo por populosas sociedades, sedentárias e possivelmente estratificadas. Essas sociedades são autóctones, ou seja, não se explicam como o resultado da difusão de culturas andinas mais 'avançadas'..." (Cunha 1992: 11-12).

$\mathrm{O}$ trecho citado refere-se à grande polêmica da historiografia da América indígena sobre a origem das chamadas "sociedades complexas" e as possiveis relações entre as populações que se desenvolveram na bacia amazônica e as chamadas "altas culturas" andinas. Esta discussão está diretamente ligada à questão do modelo de tipologias sociais de Steward aplicado aos grupos indígenas da América do Sul, e à hipótese defendida por alguns pesquisadores da existência de cacicados na Amazônia:

“... há hoje um consenso de que, nos mil anos que precederam a ocupação européia, diversas regiões da planície amazônica alcançaram um grau de desenvolvimento sócio-cultural mais complexo daquele que a etnografia tem observado desde o século XIX. A descoberta de sítios arqueológicos de dimensões inusitadas de aterros artificiais com evidências de função habitacional e funerária, esta última com elementos sugestivos de acesso diferenciado a bens materiais, levou arqueólogos a entrever a existência de formações políticas do tipo dos cacicados da área circuncaribenha. Muito embora as seqüências arqueológicas não apontem muito claramente para a contemporaneidade daquele horizonte cultural com o início da colonização, havia a expectativa de que os relatos dos primeiros viajantes trouxessem o testemunho de um modo de vida consentâneo com as evidências arqueoló- gicas e com o tipo de organização

política presumida” (Porro 1996:76).

Em "The Pristine Myth: The Landscape of the Americans in 1492", William Denevan (1992) apresenta evidências de estudos demográficos aos argumentos, cada vez mais concretos, de que a América estava densamente povoada no início do século XVI. Se os dados demográficos abstraídos de cálculos pautados exclusivamente nos relatos dos cronistas sempre foram passíveis de questionamento, os avanços tecnológicos recentes permitiram que outras fontes de pesquisa como, por exemplo, o manejo das florestas originais, a agricultura e as demais evidências da construção sistemática de uma paisagem antropogênica por assentamentos permanentes revigorassem as discussões. Ainda assim, conforme apontando anteriormente, análises fundamentadas em fatores naturais e econômicos, que recaem unicamente sobre evidências do aproveitamento dos recursos ambientais, são insuficientes quando o objetivo é tentar reconstruir a forma de organização política e social de uma determinada sociedade. Pautado nessa premissa Eduardo Góes Neves apresenta ao debate uma relativa resistência à identificação de cacicados na Amazônia. Rebatendo, por exemplo, a interpretação de Anna Roosevelt das evidências de aterros e valas nos sítios arqueológicos da Ilha de Marajó como indicativos da presença de estruturas políticas centralizadas, Góes Neves nos lembra que, mesmo podendo estar associadas à guerra, essas evidências não são suficientes para sustentar o argumento de uma centralização política. Uma possível interpretação, nas palavras do autor, estaria também na resposta local a problemas ecológicos como as cheias anuais (1999: 336). Em "Agricultural Limitations of the Amazon in Theory and Practice" Thomas Meyers (1992: 93) apresenta a mesma linha de raciocínio:

“...a presença de campos de cultivo não apenas nas áreas de várzea, mas também nas terras firme são um importante indicativo de que as primeiras poderiam ser inteiramente destruídas pela inundação. Quando isso ocasionalmente ocorreu, no século XVII, os 
indígenas recorreram à produção dos campos de terra firme, que os primeiros missionários mal sabiam da existência." (Meyers 1992: 93)

Nas conclusões do texto, Meyers afirma que a teoria das limitações ambientais da floresta tropical amazônica resulta de comparações inexatas entre o grau de complexidade social atingida pelas sociedades que lá se desenvolveram e as culturas circuncaribenhas, lembrando que muita evidência contrária foi ignorada pelos adeptos do determinismo ambiental que tem em Betty Meggers sua principal expressão (Meyers 1992: 93).

A comparação dos trabalhos citados de Eduardo Neves e Thomas Meyers nos faz perceber que, independentemente do posicionamento divergente desses autores sobre a suposta formação de cacicados amazônicos, ambos, junto a tantos autores deste debate, apresentam evidências contrárias à lógica das limitações ambientais que teriam comprometido o desenvolvimento da agricultura na Amazônia.

"Do geógrafo Carl Sauer, Lathrap herdou a perspectiva que enxergava... nos campos inundáveis das áreas de floresta tropical das terras baixas como centros remotos de desenvolvimento cultural como, por exemplo, de domesticação de plantas. Nesta perspectiva... a floresta tropical, ou partes dela, não encontrou limitações para o desenvolvimento cultural, mas, de modo contrário, enfrentou um estímulo para o estabelecimento de sociedades sedentárias estáveis..." (Neves 1996: 41)

Nesse sentido, se queremos aprofundar a discussão sobre as sociedades complexas, é necessário ampliar o espectro de análise, extrapolando a lógica do universo da produção de subsistência, para que a hipótese aumento densidade populacional > aumento de complexidade social possa ser avaliada a partir de novos pressupostos teóricos. Em outras palavras, devem-se incorporar dados que compreendem a pluralidade de opções, sobretudo as de ordem cultural, nos estudos das formas de agrupamento humano. Esses são temas que envolvem conceitos dos campos da antropologia política (Sahlins 1960, 1972; Mauss 1924, Clastres [1974] 2003) e da arqueologia cognitiva (Renfrew 2001) que, a nosso ver, tornaram-se um indispensável alicerce teórico para os estudos históricos da América Pré-colombiana. Tornou-se evidente o avanço proporcionado pelas análises interdisciplinares.

Mesmo quando o principal objetivo de certas pesquisas foi o de avaliar as possibilidades econômicas de adaptabilidade, ou as perspectivas de evolução que o ambiente conferia a um determinado grupo de assentamento permanente, a preocupação em compilar dados sobre a economia daquele grupo levou necessariamente a indagações sobre as formas de produção e distribuição de alimentos e produtos. Em outras palavras, os estudos sobre as formas de organização social e política das sociedades ameríndias levaram, necessariamente, a discussões que transcendem o âmbito local. As relações sociais passaram naturalmente a serem discutidas, também, sob a luz das relações supra-aldeanas. Assim, aquilo que poderia ser entendido pelo viés das relações de produção, passa a fazer parte de temáticas como a identificação de rotas e redes comerciais, a demarcação de fronteiras territoriais, as diferentes naturezas e possiveis relações entre chefias - e não somente a existência ou não de uma chefia nos moldes do autoritarismo despótico do Estado (Clatres 2003: 222), as formas e a legitimidade do poder (político e/ou religioso) nas relações entre grupos e, como não poderia deixar de ser, as noções e relações de guerra.

Para abordar estas questões de forma sistemática, propomos aqui uma discussão a partir de estudos de casos de sociedades classificadas na literatura como cacicados e tribos, respectivamente do Caribe e da Amazônia, atendo-nos ao conhecido debate acadêmico sobre as possíveis influências de populações amazônicas, ou do Brasil Central, nas sociedades caribenhas (Rouse 1992; Lathrap 1970; Siegel 1989, 1991b; Heckenberger e Petersen 1995; Oliver 1998). 
Tribos e cacicados no Caribe e na América do Sul: centro, chefia e relações de poder no espaço comunal

Tomemos como primeiro exemplo o estudo de caso do sítio arqueológico Caguana, localizado no centro-oeste do atual Porto Rico. Segundo o arqueólogo José Oliver (1998), Caguana pode ser interpretado como o principal centro cerimonial de Porto Rico, e talvez até do Caribe (Oliver 1998: 1; Siegel 1992). As evidências indicam que Caguana foi erigido pelos capas (c.1200-1525d.C.), antecessores diretos dos taínos. Os capas descendiam de uma longa tradição de aldeias sedentárias agricultoras e ceramistas chamada saladoide. Acredita-se que os grupos saladoides emigraram do Orinoco (Rouse 1992), muito provavelmente provindo do leito médio do rio Amazonas (Lathrap 1970; Siegel 1991a). Escavações arqueológicas realizadas nas mais antigas aldeias saladoides do atual Porto Rico demonstram que o padrão de assentamento caracterizava-se por "círculos concêntricos", padrão esse que foi muito difundido também no Brasil Central (Heckenberger y Petersen 1995; Siegel 1989).

Apoiado na hipótese dessa migração proveniente da Amazônia, Oliver demonstra que, desde os princípios da colonização saladoide das Antilhas, a praça pública servia, além de recinto para atividades cotidianas, como espaço adequado aos ritos e à organização da vida comunal. Fundamentalmente, a praça central era destinada ao enterro dos mortos. A comunicação entre descendentes (vivos) e antepassados (mortos) gerava, a partir desta função, o centro cerimonial que, como veremos adiante, explica o desenvolvimento dos cacicados.

Oliver, com base na historiografia (Siegel 1992), desenvolve o conceito da praça central nas aldeias saladoides como axis-mundi, ou espaço central de comunicação entre o mundo natural (vivente) e o "extraordinário" (dos antepassados e das essências espirituais), o que condiz com sua função de cemitério. Entre as diversas atividades rituais realizadas no espaço comunal da praça central, o autor destaca a prática do jogo de bola que, como bem explica Gillespie (1991: 332-333):

“...eram levados a cabo em momentos de disjunção, ou de separação... [por exemplo] durante os solstícios, no primeiro dia da temporada de plantação, no começo da temporada de chuvas, ou de seca..."

Gillespie afirma que "este conceito se aplica igualmente aos jogos realizados nos momentos de separação social”, exemplificando com o ritual de iniciação dos jovens apinayés, da região do Tocantins. A autora nos lembra que "os jogos estão associados ao conceito de periodicidade, porque estes introduzem ou enfatizam uma disjunção no seio da sociedade, enquanto o movimento periódico dos astros introduz uma disjunção no tempo e no espaço, separando o cosmo em noite e dia, verão e inverno..." (Gillespie 1991: 333)

Esta noção de disjunção, ou de separação, a que se refere Gillespie é parte de um conceito mais amplo de "metades" (moieties), ou dualidades, que se apresenta como um denominador comum às mais diversas formas de organização social ameríndias. Para a maioria desses grupos, o princípio dinâmico da dualidade complementar de forças antagônicas (ou de metades) é a base que sustenta o equilíbrio da natureza e do cosmo. Os princípios que regem os ciclos de vida e morte dos animais e dos homens, são os mesmos que determinam os ciclos de vida e morte das plantas, ditados pela passagem das estações do ano. São princípios que se fundamentam na concepção do tempo marcado pela observação dos astros. A rotatividade dos astros indica o tempo cíclico, ritual, da mesma forma que e a linearidade determinada no registro do calendário também indica o tempo da tradição, sendo o passado e a ancestralidade retomados no exercício ritual. Nesse sentido de relação entre as metades, a praça central saladoide funcionava como entidade coesiva, mantendo a comunidade unida por um sentido comum, como a genealogia, o parentesco e a descendência (Oliver 1998: 30-31). Por outro lado, é importante ressaltar que os "momentos de separação social" a que se 
refere Gillespie são também a ocasião em que um indivíduo se diferencia, se qualifica ou se destaca em relação ao resto do grupo. Indagamos, então: seriam esses princípios geradores de hierarquias sociais?

Similarmente aos apinayés e outros grupos de fala Macro-Jê das regiões do Araguaia e Tocantins, como por exemplo os xerentes, as aldeias saladoides do Caribe organizavam-se de forma autônoma, destituídas de sistema político supra-aldeano, constituindo grupos constituídos por linhagens, clãs e metades e com a ausência de liderança ou de caciques. Como aponta Oliver: “... podemos inferir que o costume saladoide de enterrar grupos de indivíduos na praça central da aldeia obedece à importância que se dava à organização comunal sobre a individual, acima dos interesses sócio-políticos e econômicos dos distintos segmentos da sociedade. Não é de se estranhar que nenhum enterro saladoide encontrado até hoje leve sinais de distinção de hierarquia ou status (Oliver 1998:50).

Nesse sentido, poderíamos afirmar que o debate sobre a distinção entre tribos e cacicados, pelo viés de análise sobre a centralização da chefia, pode estar associado a uma discussão anterior a respeito da essência da dualidade, ou da noção de metades, na configuração do espaço comunitário, onde eram organizadas as relações entre os indivíduos e a comunidade, e o espaço cósmico, onde eram organizadas as relações entre as comunidades, a natureza e as entidades supranaturais.

Os saladoides, assim como os apinayés e os xerentes, praticavam o jogo de bola na praça central do povoado. Curt Nimuendajú (1967: 175-177) descreve uma narrativa de origem dos apinayés, conhecida como Tecware, em que é realizado um jogo de bola na praça central. Igualmente àquilo que é observado no Popol Vuh, uma narrativa de origem mantida pelos quiché-maias da Mesoamérica, encontramos registros de que os apinayés associam o movimento da bola de borracha do Tecware à cabeça-troféu, em uma simbologia alusiva aos movimentos dos astros nas jornadas diárias do Sol e da Lua (Oliver 1998: 55).
Nota-se, portanto, que as sociedades sem chefia, ou tribais, do Caribe e da América do Sul compartilharam noções fundamentais aos modos de organização social, ritual e política: a relação entre metades, a prática do jogo de bola na praça central da aldeia e a interação das forças naturais e "extraordinárias" (como dia e a noite, a vida e a morte, o passado e o presente) a partir da atividade ritual que legitima o espaço central e coletivo da aldeia. A dinâmica dessa dualidade complementar é motora do equilíbrio estabelecido no eixo central, ou axismundi, daquela sociedade.

Os casos saladoide, apinayé e xerente citados nos ajudam a compreender a organização social de sociedades tribais nas suas relações intra-aldeanas. Contudo, se o foco deste estudo são os cacicados, deve-se observar como se dão as relações supra-aldeanas e identificar as noções de chefia e poder que, supostamente, diferem os cacicados das sociedades igualitárias, ou tribos.

Ainda no estudo do centro cerimonial de Caguana, Oliver expande sua análise para outros centros cerimoniais de Porto Rico relativos à etapa de domínio caciquil taíno. $\mathrm{O}$ autor apresenta a teoria de Vescelius (1977) sobre os centros cerimoniais localizados na periferia dos assentamentos, isto é, nas regiões fronteiriças, e não no centro geográfico da comunidade. Vescelius teria sido o primeiro autor a focar a questão dos centros cerimoniais como "fenômeno dinâmico de grande significação na política aborígine e na formação dos cacicados":

“... o elemento realmente inovador $\mathrm{e}$ revolucionário no estudo de Vescelius é a possibilidade de que os centros cerimoniais não necessariamente devem coincidir com o centro geográfico e com o assento principal de um cacicado..., mas que poderia localizar-se nas bordas ou fronteiras entre dois, três ou mais unidades políticas, cumprindo assim a função de marcar a separação ou disjunção e, a sua vez, de estabelecer um equilíbrio ou ponto de contato entre as diferentes unidades políticas. Recordamos 
aqui a função simbólica das cerimônias e rituais que a praça cumpria na aldeia apinayé do Brasil: marcar a separação entre as duas metades... e enfatizar os momentos de disjunção na sociedade, no tempo e no espaço..." (Oliver 1998: 88)

É interessante o paralelo que pode ser criado com o modelo dos "Portos de Comércio" (Ports of Trade) desenvolvido por Karl Polanyi (1957), que Anne Chapmann aplicou ao estudo de alguns sítios "periféricos" da Mesoamérica. Mesmo consideradas as limitações da análise de Chapmann, como no caso do sítio de Xoconosco (Arcuri 2003), não se pode negar que a autora propôs pensarmos possiveis relações de neutralidade nos limites fronteiriços do domínio político asteca, no século XV. As contestações que surgiram a partir do texto de Chapmann (Berdan 1976; Voohries 1991) demonstraram, por sua vez, que o estudo sistematizado das fontes prova ser inegável a necessidade de se particularizar as relações de troca, reciprocidade, conflito ou neutralidade dos sítios localizados em regiões de fronteira (de domínio político), assim como a relação centro $\mathrm{x}$ periferia no âmbito interno, quando procuramos entender territorialidade em sociedades ameríndias. Acreditamos ser esta uma problemática de abordagem indispensável ao pesquisador que discute paradigmas de centralização política e modelos evolutivos adotados nos estudo das sociedades pré-colombianas.

Observa-se na Figura 1 um mapeamento dos centros cerimoniais taínos de Porto Rico, os campos de "batey" (uma modalidade de jogo de bola). Eles estão localizados predominantemente nas regiões fronteiriças. $\mathrm{Na}$ etapa taína, os centros cerimônias não se restringiam a organizar ou equilibrar as forças sociais no âmbito intra-aldeia, mas ampliar esse equilíbrio às várias partes desiguais que funcionavam sob uma liderança caciquil (Oliver 1998: 88). No estudo sobre cacicados no Panamá, Mary W. Helms (1979: 28-29) refere-se à mesma questão com relação à prática do Krun (uma versão local do jogo de bola) como "um fórum de expressão pública da habilidade do chefe numa situação de competição e rivalidade (...) uma expressão cerimonial de prestígio..."

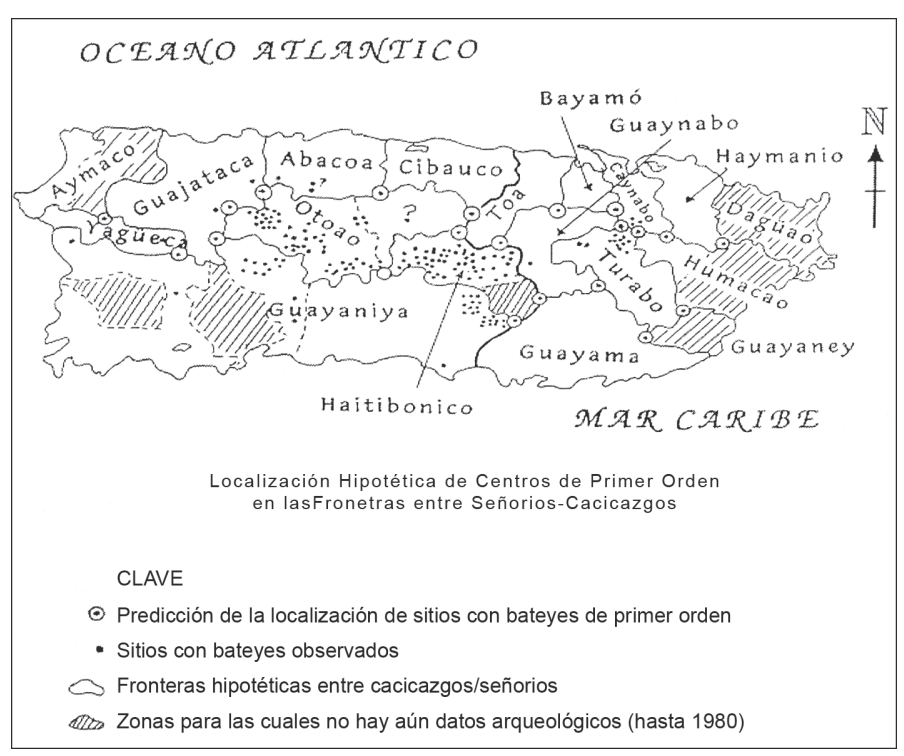

(Oliver 1998:90)

Na tese de doutorado "O Doméstico e o Ritual: cotidiano Xaray no Alto Paraguay até o Século XVI", Maria Clara Migliacio (2006: 284) discute a forma em que os Xaray, do Alto Paraguay, dispõem o espaço coletivo e ritual (dos sepultamentos) de forma circular, em torno do espaço doméstico caracterizado pela centralidade. Esta aparente 'inversão' da relação centro x periferia pode ser comparada à transferência do espaço ritual dos campos de batey às zonas de fronteira, identificada por José Oliver, no momento em que a região 'periférica' da aldeia passa a assumir função de 'centro' nas relações supra-aldeanas. No âmbito das relações supra-aldeanas, devemos pensar não apenas na coesão do grupo, mas também nas interações entre as elites. Aqui os conceitos de chefia, reciprocidade e guerra, 
assim como as noções de hierarquização, circulação e "display" (Sahlins 1972) entram em pauta, tornando-se o mote da discussão sobre o que distingue os cacicados das sociedades igualitárias.

Conforme já mencionado, os cacicados diferenciam-se das sociedades igualitárias por apresentarem pela primeira vez, na escala evolutiva dos modelos teóricos, a institucionalização do poder político e religioso centralizado. Pesquisas mais recentes demonstram, contudo, que, mais do que identificar o estágio de 'evolução social' de determinado grupo (seja ele bando, tribo, cacicado ou estado), torna-se necessário esclarecer quais os processos e os múltiplos fatores que levam uma determinada sociedade a organizar-se de forma mais ou menos hierárquica, ou "complexa".

Este é o ponto em que se nota que é impossivel dissociar por completo os estudos sobre os cacicados daqueles que buscam entender a demografia da América indígena, o que coloca a historiografia sobre a ocupação da Amazônia e os resultados mais recentes das escavações dos sítios arqueológicos de terras $\operatorname{pretas}^{4}$ da floresta tropical no centro do debate.

A partir da metade do século XX a Amazônia passa a ocupar espaço destacado nas discussões arqueológicas e antropológicas da América do Sul, sobretudo pautadas na polêmica gerada pelas publicações de Betty Meggers (1954, 1971, 1973 , 1975). As interpretações de Meggers foram amplamente debatidas ao longo das últimas três décadas. Ao deparar com claras evidências de cerâmica policrômica de iconografia elaborada e montículos artificiais na Ilha de Marajó, elementos indicativos de complexidade social, Meggers procurou explicações justificadas em uma influência externa, buscando um 'centro de origem cultural' de onde teriam migrado as populações que se assentaram na região 'ecologicamente limitada' da floresta tropical amazônica que era, por essa lógica, uma região periférica. Os

(4) Solos férteis, formados pelo sucessivo acúmulo de dejetos, ricos em fósforo e carbono negro. Sobre o assunto ver Neves 1999; Neves et al. 2001). registros arqueológicos encontrados por Meggers na Ilha de Marajó teriam resultado de ondas migratórias provenientes da região andina. Como aponta o arqueólogo Eduardo Neves:

"Meggers formulou uma hipótese sugerindo que fatores ambientais estabeleceram um limite para o potencial de desenvolvimento das sociedades amazônicas... [sugerindo] que o fator limitante fundamental seria o potencial agrícola dos solos (...) Meggers e Evans foram também influenciados pela premissa de que os Andes Centrais teriam sido o grande pólo de inovação cultural da América do Sul, e que, portanto, a Amazônia e o resto do território brasileiro teriam sido uma área marginal durante toda a PréHistória do continente" (Neves 1999: 361-362).

A limitação do ambiente amazônico teria justificado ainda, segundo Meggers, o colapso daquela ocupação complexa, o que podia ser identificado nos vestígios arqueológicos da cerâmica 'rudimentar' encontrada nos extratos mais próximos à superfície do solo (Megger e Evans 1957). Em reação aos postulados de Meggers e Evans, Donald Lathrap criou uma hipótese contrária, no início da década de 1970, sustentando que a cerâmica da América do Sul teria sido inventada dentro da Amazônia, sugerindo como centro de origem Proto-Tupi a confluência do rio Madeira com o Amazonas. Inspirado pelas propostas de Lathrap o arqueólogo José Brochado passou a avaliar, na década de 1980, as variações internas do tronco Tupi, procurando estabelecer comparações ao histórico das diferenciações cerâmicas da Amazônia. Brochado lançou a hipótese de que o aparecimento Proto-Tupi teria resultado de uma divisão entre os povos produtores da cerâmica Guarita, na Amazônia Central:

"Baseado em pressupostos da lingüística histórica, [Brochado] considerou que a diferenciação das línguas e das cerâmicas ao longo de diferentes expansões teria resultado da separação espaço-temporal 
do Proto-Tupi, causada por pressões populacionais contínuas devidas a um aumento demográfico no interior da região amazônica. Desta separação, as correlações mais evidentes ligam os Guarani às cerâmicas encontradas no oeste da Amazônia e os Tupinambá às cerâmicas do leste amazônico..." (Noelli 1996: 21)

No trecho citado, Francisco Noelli refere-se ao trabalho de Brochado, que discute a questão do centro de origem das rotas de expansão dos Tupi. Esta polêmica, como afirma o próprio autor, não está definida. Contudo, Noelli sugere que, considerando-se a comparação das informações lingüísticas, arqueológicas, etnográficas, etnobiológicas e ecológicas, “...os Tupi seriam um povo de alto sedentarismo, que teriam se expandido em conseqüência do crescimento demográfico que redundava em fracionamento de aldeias (...) implicando complexas relações interétnicas que deveriam oscilar entre contatos belicosos e amistosos" (1996: 34)

A argumentação de Noelli de 1996 foi duramente questiona por Eduardo Viveiros de Castro e Greg Urban. Viveiros de Castro criticou o abandono injustificado de um antigo modelo de migração Tupi-Guarani no sentido sul-norte, ${ }^{5}$ em favor da proposta de um modelo expansão radial, defendido por Brochado, que pressupunha o centro de origem na Amazônia Central há pelo menos 2000 anos. Viveiros de Castro postula, então, sua pergunta: “...se os povos Tupi estavam na costa atlântica há pelo menos 2000 anos, porque não chegaram a desenvolver estruturas sócio-políticas 'complexas' do tipo cacicados da várzea amazônica?” (Viveiros de Castro 1996: 59-60)

(5) É importante notar que a correlação entre os dados provenientes dos estudos lingüísticos e as evidências arqueológicas não é direta e muitos teóricos questionam este tipo de análise. Colin Renfrew (1987) discute a necessidade de se desenvolver metodologias que integrem dados arqueológicos e lingüísticos para estudar a história e o desenvolvimento das populações.
Em resposta, Noelli aceita algumas das limitações das hipóteses do modelo de expansão radial de Brochado indicadas por Viveiros de Castro e Urban, mas alega que muitos dos resultados proporcionados pela arqueologia e pelos estudos lingüísticos após 1984, ano em que Brochado publicou seus estudos, contribuíram para reafirmar alguns pontos específicos, como por exemplo a relação das cerâmicas do Alto Amazonas e da bacia do Paraná. Noelli aponta também que tampouco as interpretações dos dados arqueológicos até hoje refutam a hipótese de Brochado.

Os trabalhos de arqueologia realizados nos sítios de terras pretas da Amazônia nas últimas duas décadas colocaram à prova a teoria de Meggers e contribuíram para a mesma linha de raciocínio de Latrhap, Brochado, Noelli e Porro. A nosso ver, a discussão do centro de origem Tupi-Guarani não deve estar dissociada da polêmica hipótese de Meggers de uma expansão originada nos Andes que teria dado origem aos grupos responsáveis pela produção das complexas cerâmicas tapajônicas e marajoaras. Entre os principais trabalhos que contribuíram para esse debate nas duas últimas décadas podemos citar os dos arqueólogos Anna Roosvelt, Eduardo Neves, James Petersen, Michael Heckenberger. Em linhas gerais, esses pesquisadores propõem que as terras pretas são evidência de uma ocupação intensiva de considerável área do território amazônico em tempos pré-colombianos por sociedades que não figuravam no cenário à época da chegada dos europeus. Ademais, a iconografia da cerâmica encontrada nesses sítios apresenta-se como inegável testemunho da hierarquização e complexidade do universo ritual que caracterizou a vida das sociedades amazônicas antepassadas, como bem demonstraram as arqueólogas Denise Schaan e Denise Gomes, nos trabalhos publicados nos últimos anos. Tais evidências, pensadas à luz da discussão sobre os grupos da floresta tropical amazônica e os saladoides e taínos do Caribe, traz à tona a terceira e última questão levantada inicialmente, sobre a associação entre fatores econômicos e culturais nos modos de organização social. 
Não se pode perder de vista que os sítios de terras pretas que foram foco de pesquisa nos últimos anos estão localizados, sobretudo, nas regiões de várzea dos leitos dos principais rios da bacia hidrográfica amazônica. A questão não é tanto dissociar o potencial econômico de determinada região como atrativo para o assentamento humano, mas comparar as evidências no sentido de entender que as hipóteses lançadas pelo determinismo ecológico que influenciou tantas pesquisas realizadas na América do Sul e no Caribe não são corroboradas pela evidência arqueológica. É aqui que os fatores culturais que determinam as formas de organização social ganham peso. Se a economia e a subsistência da comunidade não podem ser ignoradas, o que devemos nos perguntar é se os critérios de avaliação de complexidade social adotados na tipologia evolucionista de Steward são adequados, a exemplo da evidência amazônica e caribenha, para classificar as sociedades ameríndias. Ou se, ao contrário, as noções de chefia não coercitiva (Clastres 2003: 223), de poder legitimado pela transformação, pela tradição e pela ancestralidade, assim como a noção de guerra como "consumo produtivo" (Viveiros de Castro 1993: 186; Seeger, Da Matta e Viveiros de Castro 1979: 3 apud Fausto 2001:328), não explicariam melhor as formas de organização social ameríndias?

Ao analisar a história dos guaranis do Brasil Meridional, John Manuel Monteiro aponta que enquanto para os tupinambás o motor da sociedade era a guerra, para os guaranis "a religião era o elemento unificador". Apoiado em Clastres, Monteiro aponta o caso guarani do conflito entre o chefe e o profeta, ou os karai, que contestavam fortemente a autoridade do chefe e, ao que indicam os relatos do XVI e XVII, atraíam grandes levas migratórias movidas pelo "messianismo".

Talvez este seja o caminho a se percorrer para discutir a pergunta de Viveiros de Castro sobre por que não se teria formado um cacicado tupi na Amazônia central. Se pensamos as noções de chefia e de guerra pautadas no poder não coercitivo, não seria mais adequado pensarmos uma interpretação pautada na idéia da Sociedade contra o Estado proposta por Clastres?

Esta é uma discussão que, a nosso ver, está longe de ser resolvida. Se por um lado não podemos negar as transformações por que passa uma sociedade frente a um expressivo aumento demográfico, o que acarreta em novos tipos de relações sociais, ditadas pela disponibilidade ou disputa de recursos; tampouco podemos ignorar que as evidências etnográficas e arqueológicas sugerem, cada vez mais, que o "Estado" talvez não fosse necessariamente o caminho almejado por grande parte das populações indígenas da América pré-colombiana. Nas palavras de Clastres:

"Se parece ainda impossível determinar as condições de aparecimento do Estado, podemos em troca precisar as condições de seu não aparecimento (...) Chefia e linguagem estão, na sociedade primitiva, intrinsecamente ligadas; a palavra é o único poder concedido ao chefe: mais do que isso, a palavra para ele é um dever (...) o chefe é generoso... somente um bom orador [como o profeta tupi-guarani do século XV] pode ter acesso à chefia (...) Palavra profética, poder dessa palavra: teríamos nela o lugar originário do poder, o começo do Estado no Verbo? Profetas conquistadores das almas antes de senhores dos homens?... o que os selvagens nos mostram é o esforço permanente para impedir os chefes de serem chefes [políticos], é a recusa da unificação, é o trabalho da conjuração do Um, o Estado" (Clastres 2003: 222 234)

Ora, a cosmovisão das sociedades ameríndias fundamentava-se no princípio da dualidade complementar, princípio esse que regulava tanto a organização ritual no espaço da praça central dos apinayés e das aldeias saladoides, quanto os jogos de bola de borracha praticados pelos capas, taínos e 
povos da Mesoamérica. Igualmente, os registros andinos indicam que a administração pública organizava-se segundo os princípios cosmológicos das metades do acima (hanan) e do abaixo (hurin), e que cada metade era administrada por duas chefias. ${ }^{6}$ Nesse sentido, não seria nossa obcecada necessidade de identificar o caminho do aparecimento do Estado e da "unidade" (Clastres 2003: 233), um passo em falso na tentativa de se compreender o passado précolombiano?

Para evitarmos a circularidade do argumento, é fundamental que o debate historiográfico seja alimentado com dados ainda inéditos, seja pela interpretação de novos vestígios arqueológicos, estudos lingüísticos, etnográficos e campos afins. O que contemplamos neste momento é que as pesquisas nas terras pretas da Amazônia Central indicam uma maior densidade demográfica na região do que se sabia, ao mesmo tempo em que há também indícios de ocupações descontínuas e que somam-se à equação os vestígios cerâmicos amazônicos com datações que superam, às vezes, a marca de 5.000 anos (Neves, Jornal da USP/XXI, 760, 2430 abril 2006: 6-7). Todos esses são fatores de suma importância, que justificam a ação permanente dos projetos de investigação, pois muito há por se preencher nas lacunas da história da América indígena.

Acreditamos, assim, que as terras baixas da América do Sul oferecem um dos campos mais promissores no sentido de re-avaliarmos os modelos de organização social propostos para as demais regiões da América pré-colombina. Em conseqüência, torna-se fundamental rever os postulados e interpretações das formas de distribuição espacial, das noções de territorialidade, das relações centro x periferia e, sobretudo, das relações de poder entre as sociedades ameríndias.

Tribes, Chiefdoms or States? Duality and power centralization in the social organization of Precolumbian America. Revista do Museu de Arqueologia e Etnologia, São Paulo, $17: 305-320,2007$.

Abstract: This paper discusses the theoretical approaches to recent archaeological and ethnographic interpretations of 'Native Americans' social and political organization. Our aim is to highlight the needs for new comparative studies that comprehend some fundamental aspects of the indigenous cosmovisions, particularly their notions of chiefdom, in order to surpass some of the limiting factors to the academic debates on social complexity and power relations in the Native America.

Keywords: Politics - Religion - Chiefdom - Indigenous America - Spatiality. 


\section{Referências bibliográficas}

ARCURI, M.M.

2003 Os sacerdotes e o culto oficial na organização do Estado mexica. Tese de Doutorado, Museu de Arqueologia de Etnologia, Faculdade de Filosofia, Letras e Ciências Humanas, Universidade de São Paulo, SP.

BAUER, B.S.

1998 The Sacred Landscape of the Inca: the Cusco Ceque System. Austin: University of Texas Press.

BERDAN, F.F.

1976 Trade, tribute and market in the Aztec empire. Austin: University of Texas Press.

BROCHADO, J.

1980 The Social Ecology in Marajora Culture. Dissertação de Mestrado, University of Illinois.

1984 An Ecological Model of the Spread of Pottery and Agriculture into Eastern South America. Tese de Doutorado, University of Illinois.

CHAPMAN, A.

1959 Puertos de intercambio en Mesoamerica prehispánica. México, Instituto Nacional de Antropología e Historia.

CLASTRES, P.

(1974) 2003A Sociedade Contra o Estado. São Paulo: Cosac \& Naify.

CUNHA, M.C.

1992 História do Índio no Brasil. São Paulo: Cia. das Letras.

DeBOER, W.

1981 Buffer Zones in the Cultural Ecology of Aboriginal Amazonia: an Ethnohistorical Approach. Latin American Antiquity, 46 (2): 364-377.

DENEVAN, W.

1992 The Pristine Myth: The Landscape of the Americas in 1492. Annals of the Association of American Geographers, 82 (3) The Americas before and after 1492: Current Geographical Research: 369-385.

FAUSTO, C.

2001 Inimigos Fiéis: História, Guerra e Xamanismo na Amazônia. São Paulo: EDUSP.

2005 Os Índios Antes do Brasil. Rio de Janeiro: Jorge Zahar Editor.

GILLESPIE, S.

1991 Ballgames and Boundaries - The Mesoamerica Balgame. Tucson: University of Arizona Press.
GOMES, D.

2005 Análise dos Padrões de Organização Comunitária no Baixo Tapajós: o Desenvolvimento do Formativo na Área de Santarém, PA. Tese de Doutorado, Museu de Arqueologia e Etnologia-USP, São Paulo.

HECKENBERGER, M.

1996 War and peace in the shadow of empire: sociopolitical change in the Upper Xingu of Southeastern Amazonia, A.D. 14002000. Tese de Doutorado, University of Pittsburg.

1998 Manioc Agriculture and Sedentism in Amazonia: the Upper Xingu Example. Latin American Antiquity, 72 (277): 633-648.

1999 The enigma of the great cities: body and state in Amazonia. In: A outra margem do Ocidente: Brasil 500 anos, experiência e destino. São Paulo: Companhia das Letras.

HECKENBERGER, M.; PETERSEN, J.

1995 Concentric Circular Village Patterns in the Caribbean: Comparisons from Amazonia. Comunicação Apresentada no XVI Congresso Internacional de Arqueologia do Caribe. Guadalupe, Basse -Terre.

HECKENBERGER, M., PETERSEN, J.; NEVES, E.G.

1999 Village size and permanence in Amazonia: two archaeological examples from Brazil. Latin American Antiquity, 10 (4): 535-76.

HECKENBERGER, M., NEVES, E.G.; PETERSEN, J.

1998 De onde surgem os modelos? As origens e expansões Tupi na Amazônia Central. Revista de Antropologia, 41 (1): 69-96.

HELMS, M.W.

1979 Ancient Panama. Austin: University of Texas Press,

KIRCHHOFF, P.

1949 The Handbook of Middle American Indians. Washington: Bureau of American Ethnology.

LATHRAP, D.

1970 The Upper Amazon. London: Thames and Hudson.

LEVI-STRAUSS, C.

1978 Myth and Meaning. New York: Schocken Books.

MAUSS, M.

1924 Essai sur le don: forme et raison de l'échange dans les socetés archaiques. Année de Sociologique, series 2, vol.1. 
MEGGERS, B.J.

1954 Environmental limitations on the development of culture. American Anthropologist, 56: 801-824.

1971 Amazonian: Man and Culture in a Counterfeit Paradise. Chicago: Aldine Atherton Inc.

1973 Some Problems of cultural adaptation in Amazonia, with emphasis on the PreEuropean Period. In: Tropical Forest Ecosystems in Africa and South America: a Comparative Review. Washington, Smithsonian Institution Press: 311-320.

1975 Application of the biological model of diversification to cultural distributions in tropical lowland South America. Biotrópica, 7 (3): 171-61.

1979 Prehistoric America, an Ecological Perspective. New York: Smithsonian Institute.

MEGGERS, B.; EVANS, C.

1957 Archaeological Investigations at the Mouth of the Amazon. Washington, Smithsonian Institution, Bureau of American Ethnology, Bulletin 167.

MÉTRAUX, A.

1942 Tribes of middle and upper Amazon River. Washington, Smithsonian Institution, Bureau of American Ethnology, Bulletin 143 (3): 687-712.

MEYERS, T.

1999 Agricultural limitations of the Amazon in Theory and Practice. World Archaeology, 24 (1), The Humid Tropics: 82-97.

OSELEY, M.

1992 The Incas and Their Ancestors: The Archaeology of Peru. London: Thames and Hudson.

NEVES, E.G.

1996 Paths in Dark Waters: Archaeology as Indigenous History of in the Upper Rio Negro Basin, Northwest Amazon. Tese de Doutorado, Indiana University.

1999 Changing Perspectives in Amazonian Archaeology. Archaeology in Latin America, London, Routledge: 216-243.

1999-2000 O Velho e o Novo na Arqueologia da Amazônia. Revista USP, Dossiê Antes de Cabral: Arqueologia Brasileira, 44: 86-111.

2006 A vida na Amazônia Pré-Colonial. Entrevista concedida ao Jornal da USP (por Sylvia Miguel), São Paulo.

NIMUENDAJÚ, C.

1967 As Lendas da Criação e Destruição do Mundo como Fundamentos da Religião dos Apocriva -Guarani. São Paulo: EDUSP, 198.
NOELLI, F.S.

1996 As Hipóteses sobre o centro de Origem e rotas de Expansão dos Tupi. Revista de Antropologia, 39 (2): 7-53.

1996 Resposta a Eduardo Viveiros de Castro e Greg Urban. Revista de Antropologia, 39 (2): $104-117$.

OBERG, K.

1949 The Terena and the Cadesco of Southern Mato Grosso, Brazil. Washington: Smithsonian Institute.

OLIVER, J.R.

1998 El Centro Ceremonial de Caguana, Puerto Rico. Oxford: Hadrian Books.

OLIVIER, G

2004 Tezcatlipoca: burlas y bromas de un dios Azteca. México: Fondo de Cultura Económica.

PLATT, T.

1978 Symetrie en miroir. Annales 33 anné septembre-décembre. Paris, Armand Coli.

PETERSEN, J. et al.

2000 Collapse among Amerindian Complex Societies in Amazonia and the Caribbean: Endogenous and/or Exogenous Factors? Comunicação apresentada na $65^{\text {a. }}$ reunião anual da Society of American Archaeology, Philadelphia.

PETERSEN, J.; NEVES, E.; HECKENBERG, M.

2001 Terra Preta and Prehistoric Amerindian Occupation in Amazonia. In: Mc Ewan, C.; Barreto, C.; Neves, E.G. (Eds.) Unknown Amazon. Londres, British Museum Press: 86-105.

POLANYI, K.

1957 Trade and market in the early empires. New York: The Free Press.

PORRO, A.

1985 Mercadorias e rota de comércio intertribal na Amazônia. Revista do Museu Paulista, São Paulo: 7-12.

1996 O Povo das Águas: ensaios de etno-história amazônica. Petrópolis, Editora Vozes.

RENFREW, C.

1987 Archaeology and Language. The puzzle of Indo-European origins. London: Jonathan Cape Ltd.

ROUSE, I.

1992 The Tainos: The Rise and Fall of the People who Greeted Columbus. New Haven: Yale University Press.

SAHLINS, $\mathrm{M}$.

1960 The Origins of Society. Scientific American, 203 (3): 76-87. 
1985 Islands of History. London: University of Chicago Press.

SAUER, C.O.

1952 Agricultural Origins and Dispersals. New York: American Geographical Society. SERVICE, E.

1962 Primitive Social Organization: an Evolutionary Perspective. New York: Random House.

1975 Origins of the Stateand Civilization. New York: W. W. Norton \& Co.

SHAAN, D.P.

2001 Os dados inéditos do Projeto Marajó (1962-1965). Revista do Museu de Arqueologia e Etnologia, São Paulo, 11: 141-164.

2004 The Camutins Chiefdom: rise and development of social complexity on Marajó Island, Brazilian Amazon. Tese de Doutorado, University of Pittsburg.

SIEGEL, P.

1989 Site Structure, Demography and Social Complexity in Early Ceramic Age of Caribbean. In: Early Ceramic Population Lifeways and Adaptation Strategies in the Caribbean. British Archaeological Reports
International Series, n. 506. Oxford, British Archaeological Reports.

1991a "Political Evolution in the Caribbean." Proceedings of the thirteenth International Congress for Caribbean Archaeology. Willemstad, Curaçao: AINA-IACA: 232-250.

1991b Migration Research in Saladoid Archaeology: A Review. The Florida Anthropologist, Special Publications, 44 (1):79-91.

1992 Ideology, Power and Social complexity in Prehistoric Puerto Rico. Tese de Doutorado. State of New York and Binghanton. Michigan: An Arbor.

STEWARD, J.

1948 Handbook of South American Indians. Washington: Bureau of American Ethnology.

VIVEIROS DE CASTRO, E.

1996 Comentário ao Artigo de Francisco Noelli. Revista de Antropologia, 39 (2): 51-60.

VOORHIES, B.

1991 La Economía del Antiguo Soconusco, Chiapas. México, Universidad Nacional Autónoma de México. 